\title{
Predictors of atrial fibrillation recurrence in patients with long-lasting atrial fibrillation
}

\author{
Michalis Efremidis $M D^{1}$, loannis $P$ Alexanian $M D^{1}$, Dimitrios Oikonomou MD ${ }^{1}$, Dimitrios Manolatos $M D^{1}$, \\ Konstantinos P Letsas MD¹, Loukas K Pappas MD¹, Gerasimos Gavrielatos MD ${ }^{1}$, Maria Vadiaka MD ${ }^{1}$, \\ Constantinos C Mihas MD MSc ${ }^{1}$, Gerasimos S Filippatos MD², Antonios Sideris MD ${ }^{1}$, Fotios Kardaras MD ${ }^{1}$
}

M Efremidis, IP Alexanian, D Oikonomou, et al. Predictors of atrial fibrillation recurrence in patients with long-lasting atrial fibrillation. Can J Cardiol 2009;25(4):e119-e124.

BACKGROUND: Limited data are available on the predictors of atrial fibrillation $(\mathrm{AF})$ recurrence in patients with chronic $\mathrm{AF}$.

OBJECTIVES: To evaluate potential clinical, echocardiographic and electrophysiological predictors of AF recurrence after internal cardioversion for long-lasting AF.

METHODS: A total of 99 consecutive patients (63 men and 36 women, mean age $63.33 \pm 9.27$ years) with long-standing AF ( $52.42 \pm 72.02$ months) underwent internal cardioversion with a catheter that consisted of two defibrillating coils. Shocks were delivered according to a step-up protocol. Clinical follow-up and electrocardiographic recordings were performed on a monthly basis for a 12-month period or whenever patients experienced symptoms suggestive of recurrent AF.

RESULTS: Ninety-three patients (93.94\%) underwent a successful uncomplicated cardioversion, with a mean atrial defibrillation threshold of $10.69 \pm 6.76 \mathrm{~J}$. Immediate reinitiation of $\mathrm{AF}$ was observed in 15 patients $(15.78 \%)$ of whom a repeated cardioversion restored sinus rhythm in 13 cases. Early recurrence of $\mathrm{AF}$ (within one week) was observed in 12 of 93 patients $(12.90 \%)$. At the end of the 12-month follow-up period, during which seven patients were lost, 42 of the 86 remaining patients (48.84\%) were still in sinus rhythm. Multivariate regression analysis showed that left atrial diameter (OR 1.126, 95\% CI 1.015 to $1.249 ; \mathrm{P}=0.025)$ and mitral A wave velocity (OR 0.972, 95\% CI 0.945 to 0.999; $\mathrm{P}=0.044$ ) were significant and independent predictors of $\mathrm{AF}$ recurrence, whereas age, left ventricular ejection fraction and AF cycle length were not predictive of arrhythmia recurrence.

CONCLUSION: The present study showed that the left atrial diameter and mitral A wave velocity are the only variables associated with AF recurrence after successful cardioversion.

Key Words: Atrial fibrillation; Internal cardioversion; Outcome; Prediction; Recurrence

\section{Prédicteurs de la récurrence de FA chez des patients qui en souffrent de longue date}

HISTORIQUE : On dispose de peu de données sur les prédicteurs de la
récurrence de fibrillation auriculaire (FA) chez des patients qui en souffrent depuis longtemps.

OBJECTIF : Évaluer les prédicteurs cliniques, échocardiographiques et électrophysiologiques potentiels de la récurrence de FA après une cardioversion interne pour FA chronique.

MÉTHODES : En tout, 99 patients consécutifs ( 63 hommes et 36 femmes, âgés en moyenne de 63,33 $\pm 9,27$ ans), souffrant de FA de longue date $(52,42 \pm 72,02$ mois $)$ ont subi une cardioversion interne au moyen d'un cathéter muni de deux sondes de défibrillation. Les chocs ont été administrés selon un protocole à énergie croissante. Un suivi clinique et des enregistrements électrocardiographiques avaient lieu sur une base mensuelle pendant 12 mois ou dès que le patient manifestait des symptômes évocateurs d'une récurrence de FA.

RÉSULTATS : Quatre-vingt-treize patients (93,94\%) ont subi une cardioversion avec succès et sans complications; le seuil de défibrillation auriculaire moyen a été de 10,69 $\pm 6,76 \mathrm{~J}$. Une récurrence immédiate de la FA a été observée chez 15 patients $(15,78 \%)$ et la reprise de la manœuvre de cardioversion a permis de rétablir un rythme sinusal chez 13 d'entre eux. Une récurrence précoce de la FA (au cours de la première semaine) s'est produite chez 12 patients sur 93 (12,90\%). À la fin de la période de suivi de 12 mois, durant laquelle sept patients ont été perdus de vue, 42 des 86 patients restants $(48,84 \%)$ maintenaient toujours un rythme sinusal. L'analyse de régression multivariée a révélé que le diamètre de l'oreillette gauche (RC 1,126, IC à $95 \% 1,015$ à $1,249, \mathrm{p}=0,025)$ et la vélocité de l'onde A mitrale (RC 0,972, IC à $95 \%$, de 0,945 à 0,999, p = 0,044) étaient des prédicteurs significatifs et indépendants de la récurrence de FA, tandis que l'âge, la fraction d'éjection ventriculaire gauche et la durée du cycle de FA n'ont pas permis de prédire la récurrence de cette arythmie. CONCLUSION : La présente étude a démontré que le diamètre de l'oreillette gauche et la vélocité de l'onde A mitrale sont les seules variables associées à la récurrence de la FA après une cardioversion réussie.

anesthesia is preferred and those who are susceptible to sinus node depression following external cardioversion $(2,4)$.

Before internal atrial defibrillation is attempted in a patient with chronic AF, it is important to determine the probability of maintaining sinus rhythm after cardioversion; thereby, procedure-related risk may be avoided and cost-effectiveness may be improved. The primary goal of the present study was to investigate the clinical, echocardiographic and electrophysiological determinants of AF recurrence after ICV of patients with long-lasting (persistent or permanent) AF. ing biphasic shocks, have increased the success rates of external cardioversion (2). Internal cardioversion (ICV) remains useful in certain groups of patients, including overweight or obese patients, patients with chronic obstructive pulmonary disease or asthma who are more difficult to defibrillate, and patients with implanted pacemakers who may be injured by high-energy shocks (3). ICV is additionally indicated in patients in whom avoidance of general

\section{METHODS}

\section{Patients}

A total of 99 patients with symptomatic AF were consecutively enrolled in the study to undergo internal atrial cardioversion. The

${ }^{1}$ Second Department of Cardiology, Evangelismos General Hospital of Athens; ${ }^{2}$ Department of Cardiology, Heart Failure Unit, Athens University Hospital Attikon, Athens, Greece

Correspondence and reprints: Dr Michalis Efremidis, Second Department of Cardiology, Evangelismos General Hospital of Athens, 45-47 Ipsilantou Street,

Athens, 10676, Greece. Telephone 30-210-720-1411, fax 30-210-935-6482, e-mail micbcar@otenet.gr

Received for publication December 21, 2006. Accepted September 23, 2007 
study protocol was approved by the Evangelismos General Hospital of Athens (Greece) ethics committee, and informed consent was obtained from each patient before the procedure. All of the patients in the study had chronic AF, which was persistent in 45 patients $(45.45 \%)$ and permanent in 54 patients $(54.54 \%)$. AF duration before ICV was estimated by obtaining a thorough clinical history as well as electrocardiograms (ECGs), including continuous ambulatory ECG recordings. Their indication for ICV was refractoriness to external cardioversion or existence of a contraindication to it. All patients were subjected to four weeks of anticoagulation treatment with a target international normalized ratio between 2 and 3 before undergoing ICV. Transesophageal echocardiography was performed $24 \mathrm{~h}$ before the procedure to exclude the existence of intracavitary thrombus.

Patients were excluded from the study if they had any of the following criteria: history of sustained ventricular arrhythmia, cardiac arrest or congenital long QT syndrome; AF due to reversible causes (eg, hyperthyroidism); history of myocardial infarction or revascularization procedure within the previous six months; left atrial thrombus diagnosed by transesophageal echocardiography the day before cardioversion; digitalis toxicity; significant electrolyte imbalance; implanted pacing device; prosthetic valve; history of embolism; pregnancy; and contraindication to anticoagulation.

\section{ICV procedure}

ICV was performed with the patient lightly sedated and in the fasting state. The administration of antiarrhythmic drugs was not interrupted for the procedure. ICV was performed in the electrophysiological laboratory after placement of the catheters under fluoroscopy.

One temporary 6 Fr catheter (Vascostim TC, VascoMed, Germany) consisting of two defibrillating coils, each $55 \mathrm{~mm}$ in length, was inserted into the left subclavicular vein and positioned in the right atrium with the proximal coil in the right high lateral atrial wall extending to the lower part of the superior vena cava. The distal coil was positioned inside the coronary sinus in 51 patients, in the pulmonary artery in 28 patients and in the right ventricular outflow tract in 20 patients. A second 6 Fr quadripolar catheter was introduced via the femoral vein in the right ventricular apex for $R$ wave sensing. A third steerable catheter consisting of 10 poles (2-5-2 mm interelectrode spacing, Biosense-Webster Inc, USA) was introduced through the same route into the lateral right atrial wall to record atrial endocardial activity. Using the distal defibrillator coil as the anode and the proximal coil as the cathode, a 31/31 ms biphasic waveform shock, synchronized with the $\mathrm{R}$ wave, was delivered from an external defibrillator (TMS 1000, Biotronik, Germany). To prevent inadvertent induction of ventricular fibrillation, shocks were delivered only after RR intervals greater than $500 \mathrm{~ms}$. The patients were sedated with $0.04 \mathrm{mg} / \mathrm{kg}$ to $0.10 \mathrm{mg} / \mathrm{kg}$ midazolam, intravenously. Shocks were delivered according to a step-up protocol from $1 \mathrm{~J}$ to $30 \mathrm{~J}(1.1 \mathrm{~J}, 2 \mathrm{~J}, 3.1 \mathrm{~J}, 4.5 \mathrm{~J}$, $5.3 \mathrm{~J}, 6.1 \mathrm{~J}, 7$ J, 8 J, 9 J, $10 \mathrm{~J}, 11 \mathrm{~J}, 12 \mathrm{~J}, 13 \mathrm{~J}, 14 \mathrm{~J}, 15 \mathrm{~J}, 17 \mathrm{~J}, 18 \mathrm{~J}, 20 \mathrm{~J}$, $21 \mathrm{~J}, 23 \mathrm{~J}, 25 \mathrm{~J}, 26 \mathrm{~J}, 28 \mathrm{~J}, 30 \mathrm{~J})$ until cardioversion of AF occurred. The time interval between the shocks was $5 \mathrm{~min}$. Atrial defibrillation threshold (ADFT) was defined as the lowest shock energy that successfully restored sinus rhythm.

Criteria for discontinuation of the procedure were patient discomfort, achievement of the maximum energy of $30 \mathrm{~J}$, or complications such as induction of proarrhythmia or major bleeding.

After successful cardioversion, all patients were started on amiodarone intravenously for the first $24 \mathrm{~h}(2 \mathrm{mg} / \mathrm{kg}$ for a $10 \mathrm{~min}$ infusion and then $15 \mathrm{mg} / \mathrm{kg}$ for a $24 \mathrm{~h}$ continuous infusion) with concurrent $24 \mathrm{~h}$ monitoring.

\section{Electrophysiological and echocardiographic parameters}

Before delivery of shock energy, ECG and endocardial electrogram recordings of $1 \mathrm{~min}$ duration were recorded and stored (Prucka Engineering Inc, USA). The AF cycle length (AFCL) was measured manually by using the calipers of the recording system at a paper speed of $100 \mathrm{~mm} / \mathrm{s}$. The mean AFCL of the last $1 \mathrm{~min}$ before shock delivery was calculated. The AFCL was measured from a single (3-4) bipolar electrogram recorded from the right high lateral atrial wall.

Echocardiographic evaluation of the patients was performed within $4 \mathrm{~h}$ after cardioversion. End-systolic left atrial diameter was measured in the parasternal long-axis view. Left ventricular ejection fraction was measured in the two-chamber apical view. Mitral valve Doppler peak flow velocities were recorded with pulsed wave Doppler at the tip of the opened mitral valvelets in the apical four-chamber view.

\section{Definitions}

$\mathrm{AF}$ is designated persistent when sustained beyond seven days or is not self-terminating. Permanent AF includes AF episodes in which cardioversion has failed.

Successful cardioversion is defined as the presence of sinus rhythm, even if there is only one sinus beat.

Immediate reinitiation of $\mathrm{AF}$ is characterized as AF resumption within $1 \mathrm{~min}$ after an internal atrial defibrillation shock that resulted in sinus rhythm for at least one beat.

Early recurrence of $\mathrm{AF}$ is defined as a relapse of AF within one week of the procedure. Late recurrence of AF is defined as a relapse of AF more than one month after the procedure (5).

\section{Patient follow-up}

All patients were evaluated clinically and electrocardiographically 10 days after cardioversion, and then on a monthly basis for a 12 -month period or on experiencing symptoms suggestive of AF recurrence. All patients were treated with class IC or III antiarrhythmic drugs and anticoagulants after cardioversion. Angiotensin-converting enzyme inhibitors, beta-blockers, calcium antagonists (nondihydropyridines), diuretics and digitalis were continued based on the clinical status of the patient.

The end point of the study was the first recurrence of AF after ICV. For patients who died or were lost to follow-up (seven of 93 patients $[7.52 \%]$ ), data collection was up to the time of the last clinical evaluation. None of the patients were lost before the completion of one month of follow-up.

\section{Statistical analysis}

Continuous variables are presented as median \pm interquartile range (25th to 75 th percentile) or mean $\pm \mathrm{SD}$, according to their distribution, while categorical variables are presented as absolute and relative frequencies (percentages). The Shapiro-Wilk criterion was used for the assessment of normality. Based on the non-normal distribution of the continuous variables in the failed cardioversion subgroup, the Mann-Whitney U test was used for the comparisons.

Univariate and multivariate logistic regression analysis estimated the OR of recurrence of AF. Deviance residuals evaluated the models' goodness of fit. The one-year recurrence was estimated using the Kaplan-Meier method, and the patients were censored at the date of recurrence of AF. Cut-off point analysis using the receiver operating characteristic curves was applied to evaluate the left atrial diameter and $\mathrm{A}$ wave velocity by which the best predictive ability regarding the recurrence of AF can be achieved. Moreover, comparisons of the areas under the receiver operating characteristic curves using the Wilcoxon test showed which marker had the best predictive ability. All reported $\mathrm{P}$ values are based on two-sided tests and compared with a significance level of 5\%. Data were analyzed using STATA statistical software (version 9.0, Stata Corporation, USA).

\section{RESULTS}

A total of 99 patients fulfilled the inclusion criteria of the study (63 men and 36 women, mean age $63.33 \pm 9.27$ years) and underwent ICV of AF. Of these 99 patients, sinus rhythm was not achieved in four patients (4.04\%). Immediate reinitiation of AF was observed in 15 patients $(15.78 \%)$. An additional shock was delivered, resulting in 13 patients successfully achieving cardioversion. Thus, 93 patients (93.94\%) were discharged from the electrophysiological laboratory in sinus rhythm. 
TABLE 1

Comparison of patients with or without successful cardioversion

\begin{tabular}{|c|c|c|c|c|c|c|c|}
\hline \multirow[b]{2}{*}{ Variable } & \multicolumn{2}{|c|}{ Successful cardioversion $(n=93)$} & \multicolumn{2}{|c|}{ Failed cardioversion $(n=6)$} & \multirow[b]{2}{*}{ P } & \multicolumn{2}{|c|}{ Total } \\
\hline & Median & $\begin{array}{l}\text { Interquartile } \\
\text { range }\end{array}$ & Median & $\begin{array}{l}\text { Interquartile } \\
\text { range }\end{array}$ & & Median & $\begin{array}{c}\text { Interquartile } \\
\text { range }\end{array}$ \\
\hline Age, years & 64 & 13 & 62 & 7 & 0.220 & 64 & 12 \\
\hline Weight, kg & 81 & 12 & 87.500 & 31 & 0.537 & 81 & 15 \\
\hline Height, cm & 168 & 13 & 173.500 & 15 & 0.208 & 168 & 12.500 \\
\hline Body mass index, $\mathrm{kg} / \mathrm{m}^{2}$ & 28.667 & 4.606 & 29.986 & 5.049 & 0.756 & 28.710 & 4.627 \\
\hline Last AF episode duration, months & 60 & 335 & 112.5 & 660 & 0.394 & 60 & 518 \\
\hline AF history, months & 447 & 2445 & 425 & 2415 & 0.959 & 447 & 2445 \\
\hline Left atrial diameter, mm & 42 & 9 & 46 & 10 & 0.327 & 42 & 9 \\
\hline Left ventricular ejection fraction, \% & 60 & 10 & 55 & 15 & 0.258 & 60 & 10 \\
\hline
\end{tabular}

AF Atrial fibrillation

TABLE 2

Baseline characteristics of patients with successful cardioversion $(n=93)$

\begin{tabular}{|c|c|}
\hline Characteristic & \\
\hline Age, years, mean $\pm S D$ & $63.52 \pm 9.46$ \\
\hline Sex, men/women & $59 / 34$ \\
\hline Weight, $\mathrm{kg}$, mean $\pm \mathrm{SD}$ & $81.48 \pm 11.18$ \\
\hline Height, cm, mean \pm SD & $162.64 \pm 30.57$ \\
\hline Body mass index, $\mathrm{kg} / \mathrm{m}^{2}$, mean $\pm \mathrm{SD}$ & $28.66 \pm 4.60$ \\
\hline $\begin{array}{l}\text { Last AF episode duration, months, } \\
\text { mean } \pm \text { SD }\end{array}$ & $22.64 \pm 45$ \\
\hline AF history, months, mean \pm SD & $52.42 \pm 72.02$ \\
\hline Left atrial diameter, $\mathrm{mm}$, mean $\pm \mathrm{SD}$ & $42.45 \pm 5.77$ \\
\hline A wave velocity, $\mathrm{cm} / \mathrm{s}$, mean $\pm \mathrm{SD}$ & $62.61 \pm 24.12$ \\
\hline LVEF, $\%$, mean \pm SD & $56.39 \pm 10.52$ \\
\hline Drugs before cardioversion* & Number of patients (\%) \\
\hline Calcium antagonists ${ }^{\dagger}$ & $12(12.90)$ \\
\hline Beta-blockers & $25(26.88)$ \\
\hline Digoxin & $32(34.41)$ \\
\hline Amiodarone & $40(43.01)$ \\
\hline ACEI & 18 (19.35) \\
\hline Drugs after cardioversion* & Number of patients (\%) \\
\hline Calcium antagonists ${ }^{\dagger}$ & $3(3.22)$ \\
\hline Beta-blockers & $7(7.53)$ \\
\hline Digoxin & $14(15.05)$ \\
\hline Amiodarone & $77(82.80)$ \\
\hline Propafenone & $9(9.67)$ \\
\hline ACEI & $19(20.43)$ \\
\hline Underlying cause of AF & Number of patients (\%) \\
\hline Idiopathic & $17(18.28)$ \\
\hline Hypertension & $48(51.61)$ \\
\hline Coronary artery disease & $11(11.82)$ \\
\hline Valvular heart disease & $6(6.45)$ \\
\hline Cardiomyopathy & $7(7.52)$ \\
\hline Congenital heart disease & $4(4.30)$ \\
\hline
\end{tabular}

*More than one possible; ${ }^{\dagger}$ Calcium antagonists refer only to diltiazem and verapamil in the present study. ACEI Angiotensin-converting enzyme inhibitor; AF Atrial fibrillation; LVEF Left ventricular ejection fraction

There were no significant differences between the clinical characteristics of the patients who left the laboratory in sinus rhythm and those who remained in AF (Table 1). The baseline characteristics of the patients with successful cardioversion are listed in Table 2.

The mean age of the patients with successful cardioversion was $63.52 \pm 9.46$ years ( 59 men and 34 women), and their mean body mass

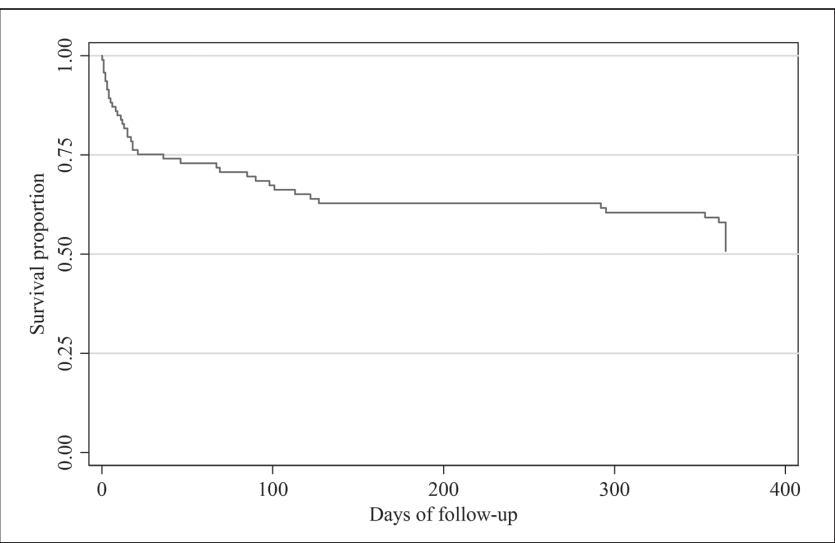

Figure 1) Kaplan-Meier survival curve for atrial fibrillation recurrence

index was $28.66 \pm 4.60 \mathrm{~kg} / \mathrm{m}^{2}$. The duration of AF at the time of study entry was $52.42 \pm 72.02$ months, and the duration of the last AF episode was $22.64 \pm 45$ months. Underlying cardiovascular disorders included hypertension in 48 patients $(51.61 \%)$, coronary artery disease in 11 patients (11.82\%), valvular heart disease in six patients $(6.45 \%)$, cardiomyopathy in seven $(7.52 \%)$ and absence of heart disease (lone $\mathrm{AF})$ in 17 patients (18.28\%). Echocardiographically measured left ventricular ejection fraction was $56.39 \pm 10.52 \%$ (range $25 \%$ to $80 \%$ ), and left atrial diameter was $42.45 \pm 5.77 \mathrm{~mm}$.

The mean AFCL was $182.87 \pm 52.64 \mathrm{~ms}$. The mean ADFT for successful restoration of sinus rhythm was $10.69 \pm 6.76 \mathrm{~J}$ (range $1.1 \mathrm{~J}$ to $30 \mathrm{~J})$.

Patients were followed every month for one year. Seven of 93 patients $(7.52 \%)$ were lost to follow-up. After cardioversion, 77 patients $(82.80 \%)$ took amiodarone and nine patients $(9.67 \%)$ took propafenone. Angiotensin-converting enzyme inhibitors, betablockers, nondihydropyridine calcium antagonists (mostly diltiazem), diuretics and digitalis were continued based on the clinical status of the patients. Anticoagulation was continued after cardioversion, and no thromboembolic phenomena were observed during the study.

After a one-year follow-up period, 42 of the 86 patients (48.84\%) were in sinus rhythm. The median time to AF relapse after cardioversion was 21 days. Twelve of 93 patients $(12.90 \%)$ had early AF recurrence within the first week, 17 of 93 patients $(18.28 \%)$ within the first two weeks (less than two weeks), 23 of 93 patients (24.73\%) within the first month, and 21 of 86 patients $(24.41 \%)$ had late recurrence (after one month) (Figure 1).

Univariate logistic regression analysis showed that AF recurrence was positively correlated with last $\mathrm{AF}$ episode duration (months) (OR 1.001; $\mathrm{P}=0.033$ ), AF duration (OR 1.0005; $\mathrm{P}=0.029$ ), left atrial diameter $(\mathrm{mm})(\mathrm{OR} 1.143 ; \mathrm{P}=0.003)$, ADFT $(\mathrm{OR} 1.066 ; \mathrm{P}=0.050)$ 
TABLE 3

Univariate logistic regression results. Atrial fibrillation (AF) recurrence is the dependent variable

\begin{tabular}{llll}
\hline Independent variables & OR & 95\% Cl & P \\
\hline Sex (men as reference), women & 0.758 & $0.311-1.844$ & 0.542 \\
Age, years & 1.02 & $0.975-1.066$ & 0.382 \\
Weight, kg & 1.003 & $0.966-1.041$ & 0.860 \\
Height, cm & 1.007 & $0.992-1.022$ & 0.378 \\
Body mass index, kg/m ${ }^{2}$ & 0.962 & $0.851-1.087$ & 0.542 \\
Last AF episode duration, months & 1.001 & $1.000-1.002$ & 0.033 \\
AF duration, months & 1.000 & $1.000-1.001$ & 0.029 \\
Left atrial diameter, mm & 1.143 & $1.046-1.249$ & 0.003 \\
A wave velocity, cm/s & 0.966 & $0.939-0.994$ & 0.018 \\
LVEF, \% & 0.965 & $0.924-1.009$ & 0.116 \\
AFCL, ms & 1.001 & $0.987-1.015$ & 0.884 \\
ADFT, J & 1.066 & $1.001-1.138$ & 0.050 \\
Drugs before cardioversion & & & \\
Amiodarone & 1.354 & $0.572-3.200$ & 0.49 \\
Digoxin & 1.142 & $0.470-2.777$ & 0.768 \\
Beta-blockers & 1.711 & $0.647-4.524$ & 0.279 \\
Calcium antagonists & 0.184 & $0.037-0.911$ & 0.038 \\
ACEl & 0.814 & $0.281-2.359$ & 0.706 \\
Drugs after cardioversion & & & \\
Amiodarone & 1.058 & $0.357-3.137$ & 0.918 \\
Digoxin & 3.823 & $1.001-15.042$ & 0.050 \\
Beta-blockers & 6.473 & $0.744-56.275$ & 0.09 \\
Calcium antagonists & 0.695 & $0.145-3.310$ & 0.648 \\
ACEl & 1.092 & $0.377-3.163$ & 0.87 \\
\hline ACEl Angion & & & \\
\hline
\end{tabular}

ACEI Angiotensin-converting enzyme inhibitors; ADFT Atrial defibrillation threshold; AFCL Atrial fibrillation cycle length; LVEF Left ventricular ejection fraction

\section{TABLE 4}

Multivariate logistic regression results. Atrial fibrillation recurrence is the dependent variable

\begin{tabular}{lccc}
\hline Independent variables & OR & 95\% Cl & $\mathbf{P}$ \\
\hline Left atrial diameter, mm & 1.126 & $1.015-1.249$ & 0.025 \\
A wave velocity, cm/s & 0.972 & $0.945-0.999$ & 0.044 \\
Sex (men as reference), women & 0.816 & $0.256-2.600$ & 0.731 \\
Age, years & 1.021 & $0.962-1.083$ & 0.491 \\
\hline
\end{tabular}

and digoxin therapy after ICV (OR 3.823; $\mathrm{P}=0.050)$, and negatively correlated with peak A wave velocity $(\mathrm{OR} 0.966 ; \mathrm{P}=0.018)$ and treatment with nondihydropyridine calcium antagonists (mostly diltiazem) before ICV (OR 0.184; $\mathrm{P}=0.038$ ) (Table 3). None of the following variables (sex, age, weight, height, body mass index, mean AFCL, treatment with amiodarone before and after ICV, treatment with angiotensin-converting enzyme inhibitors before and after ICV, and treatment with digoxin and beta-blockers before ICV) was predictive of recurrence of AF.

Multivariate logistic regression analysis (after adjusting for sex and age) (Table 4) showed that left atrial diameter (OR 1.126, 95\% CI 1.015 to $1.249 ; \mathrm{P}=0.025$ ) and peak $\mathrm{A}$ wave velocity (OR 0.972, $95 \%$ CI 0.945 to $0.999 ; \mathrm{P}=0.044$ ) were the only independent predictors of AF recurrence.

The cut-off point analysis showed that left atrial diameter larger than $44 \mathrm{~mm}$ was the optimal point that discriminated those who recurred to AF from the rest of the patients (sensitivity $58.14 \%$ and specificity $76.14 \%$ ). Similarly, the optimal cut-off point for A wave velocity was $51.9 \mathrm{~cm} / \mathrm{s}$ (sensitivity $62.86 \%$ and specificity $83.78 \%$ ). Finally, the area under the curve for left atrial diameter and A wave

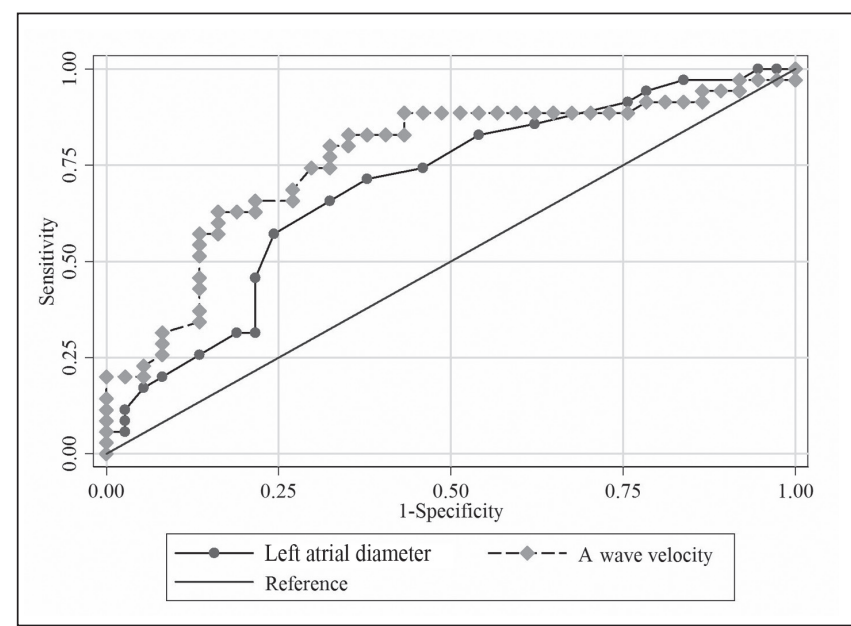

Figure 2) Plot of receiver operating characteristic for left atrial diameter and A wave velocity assessing atrial fibrillation recurrence. Left atrial diameter cut-off point: $44 \mathrm{~mm}$ (sensitivity 58.14\%, specificity 76.14\%); A wave velocity cut-off point: $51.9 \mathrm{~cm} / \mathrm{s}$ (sensitivity $62.86 \%$, specificity $83.78 \%$ )

velocity were $70.16 \%$ and $76.37 \%$, respectively (Figure 2 ). The two areas under the curve did not differ significantly $(\mathrm{P}=0.371)$.

\section{DISCUSSION}

The therapeutic approach to patients with AF primarily involves drug therapy for either rhythm or rate control. Large prospective randomized studies, such as Atrial Fibrillation Follow-Up Investigation of Rhythm Management (AFFIRM) (6) and Rate Control versus Electrical Cardioversion (RACE) (7), have shown no superiority of rhythm control versus rate control with respect to mortality $(6,8)$, stroke $(8-10)$ or quality of life (8). There was, however, a trend toward lower mortality in the rate control arm of the AFFIRM study, probably due to the deleterious effects of the antiarrhythmic drugs used $(8,11)$. It should also be noted that a subgroup of patients in AFFIRM (11) and Danish Investigations of Arrhythmia and Mortality on Dofetilide (DIAMOND)-congestive heart failure $(12,13)$ studies who remained in sinus rhythm after cardioversion, finally showed a better clinical outcome.

The present study examined the prognostic significance of several clinical, echocardiographic and electrophysiological variables for AF recurrence. Interestingly, only a few studies have investigated predictors of AF recurrence in patients with a long duration of AF after successful cardioversion. According to our results, there are two echocardiographic indexes that might predict the recurrence of AF in these patients: left atrial diameter and peak $\mathrm{A}$ wave velocity.

The success rate of ICV in our study (93.94\%) is slightly higher than that reported in other studies (14-17) using this technique, where success rates range from $75 \%$ to $90 \%$. One reason for this discrepancy may be the usage of a higher maximal energy in our study. The mean ADFT for successful cardioversion of AF was $10.69 \pm 6.76 \mathrm{~J}$, which is higher than the mean ADFT applied in other published studies $(14-18)$. The higher energy required in our study may be because we used a different system for ICV, with a biphasic shock of $31 / 31 \mathrm{~ms}$, which is quite different from the usual $3 / 3 \mathrm{~ms}$ biphasic shocks used in other studies. The use of defibrillation configuration of the pulmonary artery and the right ventricular outflow tract in $50 \%$ of our patients might also contribute to the higher energy used because it is well known that the defibrillating energy is lower when a coronary sinus configuration is used (19).

One year after successful cardioversion, 42 of 86 patients (48.84\%) remained in sinus rhythm. All of the patients were treated with antiarrhythmic drugs, mainly amiodarone. The rate of sinus rhythm maintenance in our study is lower than that reported in studies (50\% to 73\%) 
that enrolled patients with long-lasting AF refractory to external electrical cardioversion $(20,21)$. This difference might be due to varying demographic characteristics of the patients who participated in these studies, varying extent of heart disease as well as duration of the last episode of AF.

The median time of AF relapse after cardioversion was 21 days. This observation is consistent with the process of reverse electrical remodelling of the atrium one week to 30 days after resumption of sinus rhythm. During this phase of reverse electrical remodelling, the atrium is at increased risk for AF recurrence. According to Tieleman et al (22), AF recurrence is more likely to occur within the first week after cardioversion. Manios et al (23) showed that the course of shortening of the $\mathrm{P}$ wave is slower than the effective refractory period. $\mathrm{P}$ wave duration is restored within one month.

Predictors of AF recurrence were longer last AF episode duration, longer AF duration, increased left atrial diameter, higher ADFT, and digoxin therapy after ICV, while peak A wave velocity and treatment with nondihydropyridine calcium antagonists before ICV were negatively correlated with AF recurrence. Two of these factors - the left atrial diameter and the peak A wave velocity - were independent predictors of $\mathrm{AF}$ relapse after cardioversion in multivariate analysis. Bollmann et al (24) found that systolic left atrial area obtained by echocardiography may predict early AF recurrence in patients with persistent AF. Olshansky et al (25) reported that in the AFFIRM study, the left atrial diameter was correlated with AF recurrence. In Stroke Prevention in Atrial Fibrillation (SPAF)-I and -II trials, AF reccurence was predicted by advancing age, presence of congestive heart failure, previous myocardial infarction and left atrial diameter (26). Spiecker et al (27) found that a single measurement of mitral peak A wave velocity one day following cardioversion is predictive of AF recurrence, and that the time to recovery of left atrial function is related to several factors such as the duration of AF before cardioversion and the mode of cardioversion (27).

Animal and human studies $(28,29)$ have shown that digoxin potentiates the shortening of atrial effective refractory period and predisposes toward further episodes of AF. Digoxin already has been recognized as exerting a potentially deleterious effect in patients who

\section{REFERENCES}

1. Kannel WB, Abbott RD, Savage DD, McNamara PM. Epidemiologic features of chronic atrial fibrillation: The Framingham study. N Engl J Med 1982;306:1018-22.

2. Levy S. Internal defibrillation: Where we have been and where we should be going? J Interv Card Electrophysiol 2005;13(Suppl 1):61-6.

3. Waller C, Callies F, Langenfeld H. Adverse effects of direct current cardioversion on cardiac pacemakers and electrodes. Is external cardioversion contraindicated in patients with permanent pacing systems? Europace 2004;6:165-8.

4. Boriani G, Biffi M, Camanini C, Luceri RM, Branzi A. Transvenous low energy internal cardioversion for atrial fibrillation: A review of clinical applications and future developments. Pacing Clin Electrophysiol 2001;24:99-107.

5. Fuster V, Ryden LE, Cannom DS, et al. ACC/AHA/ESC 2006 guidelines for the management of patients with atrial fibrillation: Full text: A report of the American College of Cardiology/ American Heart Association Task Force on practice guidelines and the European Society of Cardiology Committee for Practice Guidelines (Writing Committee to Revise the 2001 guidelines for the management of patients with atrial fibrillation) developed in collaboration with the European Heart Rhythm Association and the Heart Rhythm Society. Europace 2006;8:651-745. (Erratum in 2007;9:856).

6. Corley SD, Epstein AE, DiMarco JP, et al. Relationships between sinus rhythm, treatment, and survival in the Atrial Fibrillation Follow-Up Investigation of Rhythm Management (AFFIRM) study. Circulation 2004;109:1509-13.

7. Hagens VE, Ranchor AV, Van SE, et al; RACE Study Group. Effect of rate or rhythm control on quality of life in persistent atrial fibrillation. Results from the Rate Control versus Electrical Cardioversion (RACE) study. J Am Coll Cardiol 2004;43:241-7. have the vagotonic type of paroxysmal AF (30). The results of the univariate analysis in the present study suggest that digoxin may facilitate or promote early recurrences of $\mathrm{AF}$ after conversion to sinus rhythm.

Our data depicted that pretreatment with nondihydropyridine calcium antagonists decreases the recurrence rate of AF after successful cardioversion. Tieleman et al (31) showed that pretreatment with calcium-lowering agents reduced recurrence rates in their patients during the first postconversion month. Of note, in our study, treatment with angiotensin-converting enzyme inhibitors after cardioversion to sinus rhythm was not predictive of sinus rhythm maintenance.

Another observation of our study that contradicts existing data $(25,32)$ is the effect of the AFCL on AF recurrence. Even though we found that short AFCL was associated with increased ADFT, there was no correlation between AFCL and AF recurrence. Rait et al (33) also did not find any association between atrial refractoriness and AF recurrence. A possible explanation for this inconsistency is the fact that our study consisted of patients with a long duration of AF. In these patients, structural and anatomical derangements have already occurred, thus sinus rhythm restoration does not result in immediate reversal of the structural remodelling, which remains the main determinant of AF recurrence (34).

\section{Study limitations}

AF duration data were derived from the patient's history and ECG recordings; thus, the existence of asymptomatic AF cannot be excluded and the duration of AF might not be accurate. The asymptomatic episodes of AF may also confound the results of AF recurrence during the follow-up. Atrial electrograms were recorded at only one atrial site, and the AF-induced changes in the electrophysiological parameters from one site may not be applicable to other parts of the atrium.

\section{CONCLUSIONS}

In our study, approximately one-half of the patients maintained sinus rhythm after ICV, during one year of follow-up. The left atrial diameter and $\mathrm{A}$ wave velocity were independent predictors of AF recurrence.

8. Wyse DG, Waldo AL, DiMarco JP, et al; Atrial Fibrillation Follow-up Investigation of Rhythm Management (AFFIRM) Investigators. A comparison of rate control and rhythm control in patients with atrial fibrillation. N Engl J Med 2002;347:1825-33.

9. Sherman DG, Kim SG, Boop BS, et al; National Heart, Lung, and Blood Institute AFFIRM Investigators. Occurrence and characteristics of stroke events in the Atrial Fibrillation Follow-up Investigation of Sinus Rhythm Management (AFFIRM) study. Arch Intern Med 2005;165:1185-91.

10. Van Gelder IC, Hagens VE, Bosker HA, et al; Rate Control versus Electrical Cardioversion for Persistent Atrial Fibrillation Study Group. A comparison of rate control and rhythm control in patients with recurrent persistent atrial fibrillation. N Engl J Med 2002;347:1834-40.

11. Steinberg JS, Sadaniantz A, Kron J, et al. Analysis of cause-specific mortality in the Atrial Fibrillation Follow-up Investigation of Rhythm Management (AFFIRM) study. Circulation 2004;109:1973-80.

12. Torp-Pedersen C, Moller M, Bloch-Thomsen PE, et al. Dofetilide in patients with congestive heart failure and left ventricular dysfunction. Danish Investigations of Arrhythmia and Mortality on Dofetilide Study Group. N Engl J Med 1999;341:857-65.

13. Pedersen OD, Bagger H, Keller N, Marchant B, Kober L, Torp-Pedersen C. Efficacy of dofetilide in the treatment of atrial fibrillation-flutter in patients with reduced left ventricular function: A Danish investigations of arrhythmia and mortality on dofetilide (diamond) substudy. Circulation 2001;104:292-6.

14. Levy S, Ricard P, Lau CP, et al. Multicenter low-energy transvenous atrial defibrillation (XAD) trial results in different subset of atrial fibrillation. J Am Coll Cardiol 1997;29:750-5.

15. Levy S, Ricard P, Gueunoun M, et al. Low-energy cardioversion of spontaneous atrial fibrillation. Immediate and long-term results. Circulation 1997;96:253-9. 
16. Taramasco V, Socas A, Ricard P, Levy S. Internal low-energy cardioversion: A therapeutic option for restoring sinus rhythm in chronic atrial fibrillation after failure of external cardioversion. Europace 1999;1:179-82.

17. Lau CP, Lok NS. A comparison of transvenous atrial defibrillation of acute and chronic atrial fibrillation and the effect of intravenous sotalol on human atrial defibrillation threshold. Pacing Clin Electrophysiol 1997;20:2442-52.

18. Boriani G, Biffi M, Bronzetti G, et al. Efficacy and tolerability in fully conscious patients of transvenous low energy internal atrial cardioversion for atrial fibrillation. Am J Cardiol 1998;81:241-4.

19. Alt E, Schmitt C, Ammer R, et al. Effect of electrode position on outcome of low-energy intracardiac cardioversion of atrial fibrillation. Am J Cardiol 1997;79:621-5.

20. Boriani G, Biffi M, Pergolini F, Zannoli R, Branzi A, Magnani B. Low-energy internal atrial cardioversion in atrial fibrillation lasting more than a year. Pacing Clin Electrophysiol 1999;22:243-6.

21. Schmitt C, Alt E, Plewan A, et al. Low energy intracardiac cardioversion after failed conventional external cardioversion of atrial fibrillation. J Am Coll Cardiol 1996;28:994-9.

22. Tieleman RG, Van Gelder IC, Crijns HJ, et al. Early recurrences of atrial fibrillation after electrical cardioversion: A result of fibrillation induced electrical remodelling of the atria? J Am Coll Cardiol 1998;31:167-73.

23. Manios EG, Kanoupakis EM, Chlouverakis GI, Kaleboubas MD, Mavrakis HE, Vardas PE. Changes in atrial electrical properties following cardioversion of chronic atrial fibrillation: Relation with recurrence. Cardiovasc Res 2000;47:244-53.

24. Bollmann A, Hussser D, Steinert R, et al. Echocardiographic and electrocardiographic predictors for AF recurrence following cardioversion. J Cardiovasc Electrophysiol 2003;14:S162-5.
25. Olshansky B, Heller EN, Brent L, et al. Are transthoracic echocardiographic parameters associated with atrial fibrillation recurrence or stroke? J Am Coll Cardiol 2005;45:2026-33.

26. Flaker GC, Fletcher KA, Rothbart RM, Halperin JL, Hart RG. Clinical and echocardiographic features of intermittent atrial fibrillation that predict recurrent atrial fibrillation. Stroke Prevention in Atrial Fibrillation (SPAF) Investigators. Am J Cardiol 1995;76:355-8.

27. Spiecker M, Bohm S, Borgel J, et al. Doppler echocardiographic prediction of recurrent atrial fibrillation following cardioversion. Int J Cardiol 2006;113:161-6.

28. Tieleman RG, Blaauw Y, Van Gelder IC. Digoxin delays recovery from tachycardia induced electrical remodeling of the atria. Circulation 1999;100:1836-42.

29. Sticherling C, Oral H, Horrocks J, et al. Effects of digoxin on acute, atrial fibrillation-induced changes in atrial refractoriness. Circulation 2000;102:2503-8.

30. Coumel P, Attuel P, Lavallee J. The atrial arrhythmia syndrome of vagal origin. Arch Mal Coeur Vaiss 1978;71:645-56.

31. Tieleman RG, De Langen C, Van Gelder IC, et al. Verapamil reduces tachycardia-induced electrical remodeling of the atria. Circulation 1997;95:1945-53.

32. Biffi M, Boriani G, Bartolotti M, Bacchi Reggiani L, Zannoli R, Branzi A. Atrial fibrillation recurrence after internal cardioversion: Prognostic importance of electrophysiological parameters. Heart 2002;87;443-8.

33. Rait M, Kusumoto W, Giraud G, McAnulty J. Electrophysiologic predictors of the recurrence of persistent atrial fibrillation within 30 days of cardioversion. Am J Cardiol 2004;93:107-10.

34. Allessie M, Ausma J, Schotten U. Electrical, contractile and structural remodeling during atrial fibrillation. Cardiovasc Res 2002;54:230-46. 